As in previous issues, entries are arranged alphabetically first by universities, and then under the university by departments. There are a name list and an alphabetical subject index to research programmes. Although some major institutions have supplied no information, this is a formidable volume running to nearly six hundred pages.

\section{Nuclear Engineering}

The Temple Press is to be congratulated on the high quality of the first number of its new publication, Nuclear Engineering (1, No. 1; April 1956; $3 s .6 d$. per copy, annual subscription 42s.). This journal should appeal not only to qualified engineers engaged in the design of nuclear reactors, but also to those interested in the uses of radioactive isotopes, or in the instrumentation associated with these two topics. Of the fourteen articles, five give details of particular reactors, one outlines the Central Electricity Authority's plans for the generation of electrical power by nuclear fuel, two deal with the production, transport and disposal of radioactive isotopes, and one with instrumentation. The remaining articles discuss the training of nuclear engineers, the Harwell Reactor School, the structure of the United Kingdom Atomic Energy Authority and the development of glandless pumps. The final article is "An Introduction to Nuclear Energy". An interesting section of this journal, and one which will be a regular feature, includes editorial comments, news items, both from home and from abroad, of interest to those connected with nuclear engineering, trade events and developments, and personalia. There are also abstracts of technical papers and a section dealing with processes and equipment, both of which should assist many who find difficulty in keeping abreast of the very rapid development of this field. Advertisements from nearly one hundred advertisers show the very large part that industry is now playing in the development of nuclear energy in Britain. Finally, the Temple Press shows its awareness of the necessity for training nuclear engineers to a high standard by its announcement of a postgraduate scholarship, tenable at any British university, for studies directed towards the engineering aspects of nuclear energy.

\section{New Form of Science Abstracts}

Commencing with the January issues (Vol. 59), both Physics Abstracts and Electrical Enqineering Abstracts, Sections $A$ and $B$, respectively, of Science Abstracts, appear in a completely new form. The page size has been increased to 11 in. $\times 8 \frac{1}{2}$ in., and the text is printed by photolithography from typewritten material, the whole of the typing and mounting being done in the office of Science Abstracts. The adoption of this new method has long been contemplated, not only because of the increasing cost of good letterpress printing, but also because it is technically better suited to the production of a periodical like Science Abstracts than the orthodox methods of printing. The abstracts are typed and corrected for press, arranged in order for the monthly issue and the papers made-up by pasting the abstracts into position. Once the pages have been photographed, no further proof-reading is necessary. Fresh items can be included up to a very late stage in the process. This method, which is not possible with ordinary metal-type printing, saves considerable time, and it is hoped, also, that there will eventually be considerable advantage in the publication of the annual indexes, by the development of new methods of assembling and reproducing the entries. Though the now form cannot equal the standard of good letterpress print. ing, by the use of semi-automatic electric typewriters a high standard of appearance, clarity and legibility is achieved. The increased page-size allows a longer line to be used. Apart from the increased page size and the new method of printing, no other change has been made in the preparation of the abstracts, and the contents, classification and indexing follow the accustomed pattern. Each abstract is given its appropriate Univorsal Decimal Classification number and headed by the English title of the article, the authors' names and the location of the article, together with a statement of the language, if foreign. The length of the article is also indicated.

\section{Daedalus : a Journal of the American Academy of Arts and Sciences}

THE journal which in the future will appear under the title of Daedalus (86, No. 1 ; 1955) is, in fact, the continuation of the Proceedings of the American Academy of Arts and Sciences, the volume serial numbers of the Proceedings being continued. The charter of incorporation granted to the American Academy of Arts and Sciences by the Massachusetts Legislature in 1780 summarized the purpose of the Academy as being "to cultivate every art and science which may tend to advance the interest, honor, dignity, and happiness of a free, independent, and virtuous people". The new Daedalus does not aim at popularization, but it hopes to attract the interest of all classes of scholars. In the experimental stages, it will appear at irregular intervals, with not less than two issues in each calendar year, but eventually it is hoped that regular quarterly numbers may become possible. The present number includes articles on Daedalus; a catalogue of $H$ (II) Regions in the Milky Way; physical problems of photosynthesis ; Count Rumford on photosynthesis; publishing the papers of great men; and art as the function of an audience.

\section{Centre International d'Epistémologie génétique}

As a result of a grant from the Rockefeller Foundation, the Centre International d'Epistémologie génétique was recently established in the Faculty of Science, University of Geneva, under the direction of Prof. Jean Piaget. The Centre, which was opened on October 1, 1955, is an interdisciplinary one, and is closely asssociated with the Department of Psychology, University of Geneva. It consists of a team of research workers (from the logico-mathematical, natural and psychological sciences) interested in the experimental and theoretical study of developmental behaviour. Its members are L. Apostel (logic and axiomatization in behavioural science), B. Inhelder (child devolopment), B. Mandelbrot (language, decision theory and information theory), W. Mays (logical machines and cybernetic models), A. Morf (research on mental development of logical reason. ing), J. Piaget (genetic psychology) and J. Rutschmann (genetical evolution of perception and physiological mechanisms). The general topic of study for the present year is the relation between logical structures and the behaviour and thought of the subject in his development. A guest symposium on this topic will be held in July next, when the first publication of the Centre will also appear. Inquiries and correspondence should be addressed to the acting secretary, Mlle. S. Taponier, Centre International d'Epistémologie génétique, Geneva 14. 